\title{
Влияние плазмохимической модификации поверхности на электронный транспорт и работу выхода в кремниевых кристаллах
}

\author{
(C) P.К. Яфраров \\ Саратовский филлиал Института радиотехники и электроники им. В.А. Котельникова Российской академии наук, \\ 410019 Саратов, Россия \\ E-mail: pirpc@yandex.ru
}

(Получена 22 января 2018 г. Принята к печати 21 февраля 2018 г.)

Исследованы закономерности модификации поверхности кремниевых кристаллов при СВЧ плазменной микрообработке в различных химически активных газовых средах. Показано, что модификация обусловлена формированием встроенных поверхностных потенциалов, которые в зависимости от типа электропроводности полупроводников различным образом влияют на автоэмиссионные свойства и приповерхностный электронный транспорт в устройствах, изготовленных на их основе.

DOI: $10.21883 /$ FTP.2019.01.46981.8826

\section{1. Введение}

Важной особенностью полупроводников является сильная зависимость их электрических и оптических свойств от состояния поверхности и способов ее обработки. При любых физико-химических обработках, связанных с получением атомно-чистых поверхностей, полупроводниковые кристаллы-подложки помимо собственных поверхностных состояний, обусловленных прерыванием периодичности потенциала кристаллической решетки, приобретают и другие, несобственные поверхностные состояния, обусловленные возмущением потенциала идеальной атомно-чистой поверхности. Наличие локальных поверхностных уровней энергии приводит к тому, что электроны и дырки могут „прилипать“ к поверхности, образуя поверхностный электрический заряд. При этом под поверхностью формируется равный по величине и противоположный по знаку пространственный заряд, который приводит к перераспределению подвижных носителей заряда и изменению приповерхностных свойств полупроводников. Дополнительные модификации вносит реконструкция поверхности [1]. Подобные электронные модификации поверхности полупроводников проявляются в ослаблении явлений, связанных с использованием эффектов поля, люминесценции, фото- и поверхностной проводимости, в изменении работы выхода [1,2].

Цель работы - исследование влияния плазменной микрообработки в различных химически активных газовых средах на автоэмиссионные свойства кристаллов кремния и электронный транспорт в гетероструктурах на их основе.

\section{2. Методика и результаты экспериментов}

Эксперименты проводились в вакуумной установке с использованием СВЧ ионно-плазменного источника, описанного в работе [3]. Мощность СВЧ-излучения и индукция магнитного поля, соответствующая возникновению в зоне газового разряда электронно-циклотронного резонанса (ЭЦР), составляли соответственно 250 Вт и 875 Гс. Давление рабочих газов в процессе плазменной обработки было равным 0.1 Па и обеспечивало выполнение условий ЭЦР, при котором степень ионизации плазмы составляла $\sim 5 \%$ [3]. В экспериментах использовались кристаллы кремния ориентации (100) различных типов проводимости: КЭС $(0.01-0.02)$ и КДБ (0.01-0.02). В качестве рабочих газов для травления пластин кремния, пассивированных тонкой пленкой естественного окисла, использовались хладон-14 и аргон. Величины ускоряющих напряжений на подложкодержателе в процессах плазменного травления были фиксированными и составляли -100 В. Исследование автоэмиссионных свойств проводилось на наноструктурированых поверхностях кристаллов кремния. Процесс наноструктурирования осуществлялся в одном технологическом цикле и включал в себя плазменное травление в хладоне-14 или аргоне с последующими плазмохимическим осаждением на кристаллы кремния островковых субнаноразмерных углеродных масочных покрытий и высокоанизотропным травлением для получения наноразмерных столбчатых кремниевых выступов [4]. Высокоанизотропное травление матрицы кремния осуществлялось при положительном смещении на подложкодержателе с использованием хладона-14 при давлении менее 0.1 Па. Исследования автоэмиссионных свойств осуществлялись в условиях высокого вакуума $\left(10^{-5}\right.$ Па) на диодной структуре, способной изменять расстояние между электродами с точностью до 1 мкм.

Наноморфология наноструктурированных поверхностей кристаллов кремния изучалась с помощью сканирующего атомно-силового микроскопа (ACM) P4-SPM-MDT. В качестве зонда использовались стандартные кремниевые кантилеверы CSG10 пирамидаль- 
ной формы с радиусом закругления 10 нм и жесткостью $0.1 \mathrm{H} /$ м. Поле сканирования составляло $3 \times 3$ мкм. Обработка результатов измерений производилась с использованием программного обеспечения микроскопа.

Исследовано влияние плазмохимической обработки на поперечный (направленный перпендикулярно поверхности кристалла) и продольный транспорт носителей заряда по схеме, обычно используемой при измерениях эффекта поля. Исследования поперечного электронного транспорта осуществлялись после низкоэнергетичного СВЧ плазмохимического травления кристаллов кремния в среде хладона-14 или аргона и осаждения в одном вакуумном технологическом цикле в плазме смеси паров этанола и моносилана герметизирующего туннельно-тонкого (10-20 нм) слоя аморфного гидрогенезированного карбида кремния. Затем на поверхность гетероструктуры методом вакуумного термического осаждения наносились металлические контакты диаметром 2 мм. При исследованиях продольного транспорта после СВЧ плазмохимического травления в среде хладона-14 или аргона на подзатворную область структуры осаждались герметизирующий туннельно-тонкий $(10-20$ нм) слой карбида кремния и слой диоксида кремния толщиной 0.5 мкм. На области стока и истока осаждался слой аморфного кремния толщиной 20 нм. Затем на все области наносились металлические контакты. Фиксирование результатов измерений производилось с применением АЦП. Подача напряжений осуществлялась с помощью двухканального блока ATTEN APS3005S-3D.

\section{1. Влияние плазмохимической обработки на автоэмиссию кристаллов кремния}

На рис. 1, 2 приведены зависимости параметров наноморфологии и автоэмиссии поверхностно-наноструктурированных кристаллов кремния от длительности высокоанизотропного масочного травления с использованием островковых наноразмерных углеродных покрытий в качестве маски после удаления естественного оксидного покрытия в низкоэнергетичной плазме аргона. Можно видеть, что характер зависимостей морфологических параметров от длительностей масочного травления кристаллов кремния различных типов проводимости практически одинаков. В отличие от этого характер изменения автоэмиссионных характеристик существенно зависит от типа электропроводности полупроводника. Для кристаллов кремния $n$-типа наименьшие значения порога начала автоэмиссии и наибольшие максимальные плотности автоэмиссионных токов реализуются при длительностях масочного травления 30 мин. Для кристаллов кремния $p$-типа оптимальная длительность масочного травления составляет 20 мин. При практически одинаковых морфологических параметрах с кремнием $n$-типа при данной длительности травления максимальная плотность автоэмиссионного тока на кремнии $p$-типа в разы больше.
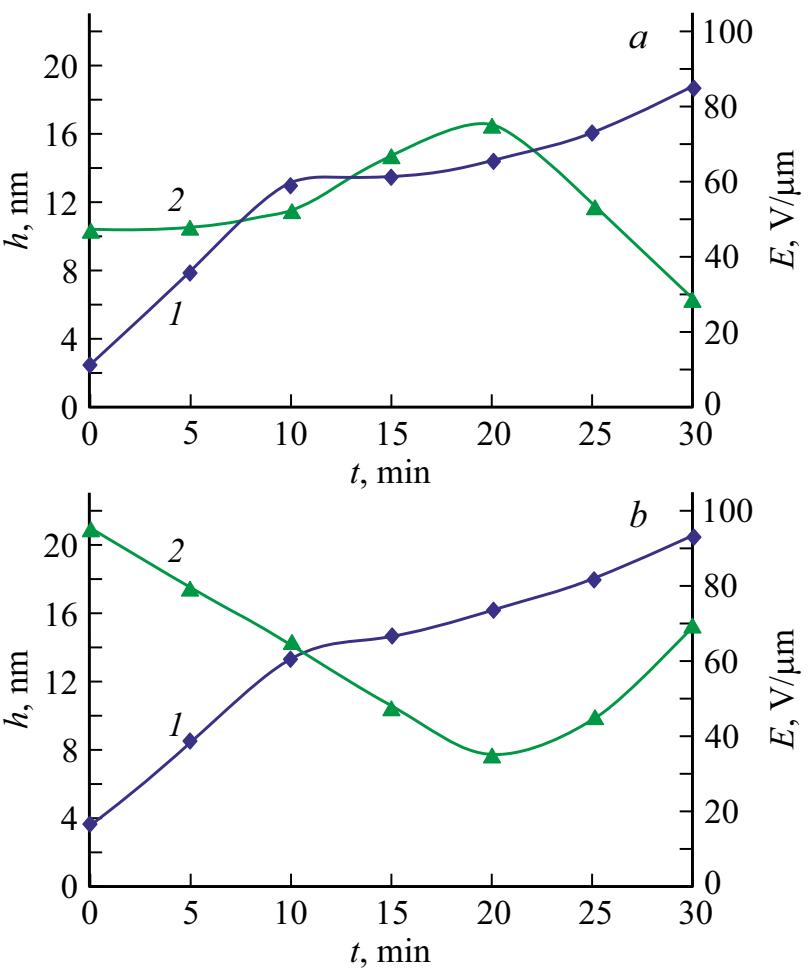

Рис. 1. Зависимости высот выступов (1) и порогов возбуждения автоэмиссии (2) от длительности масочного травления пластин кремния $(100) n$ - $(a)$ и $p$-типов $(b)$ с предварительной обработкой в плазме аргона.
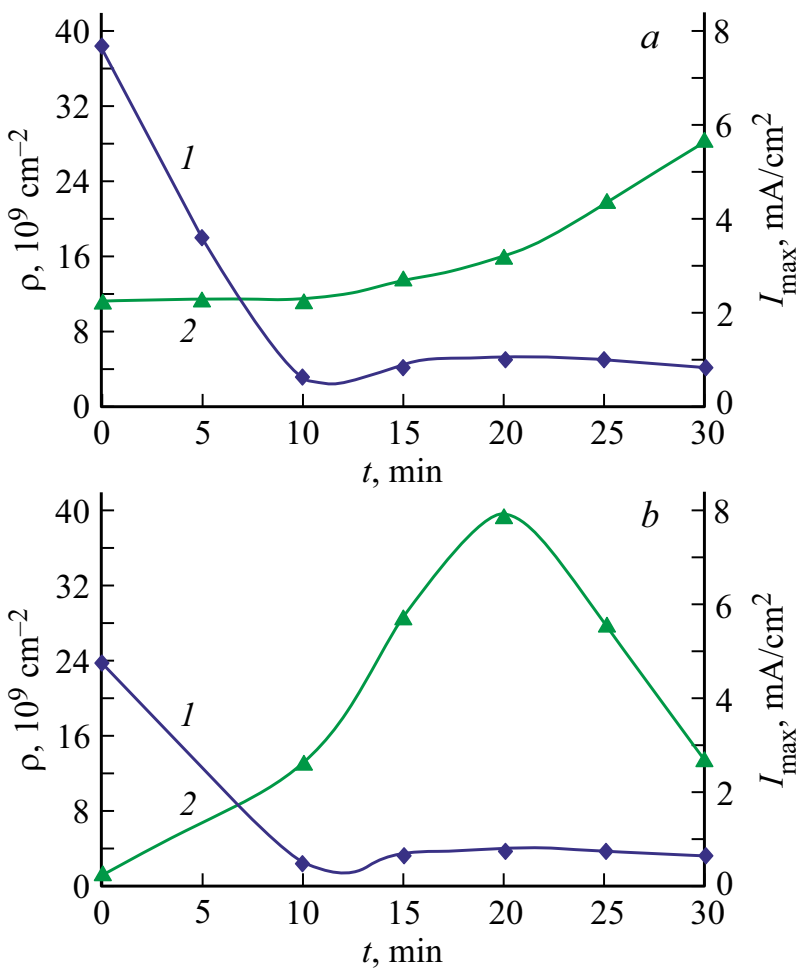

Рис. 2. Зависимости поверхностных плотностей выступов (1) и плотностей максимальных токов автоэмиссии (2) от длительности масочного травления кремния $(100) n$ - $(a)$ и $p$-типов $(b)$ с предварительной обработкой в плазме аргона. 

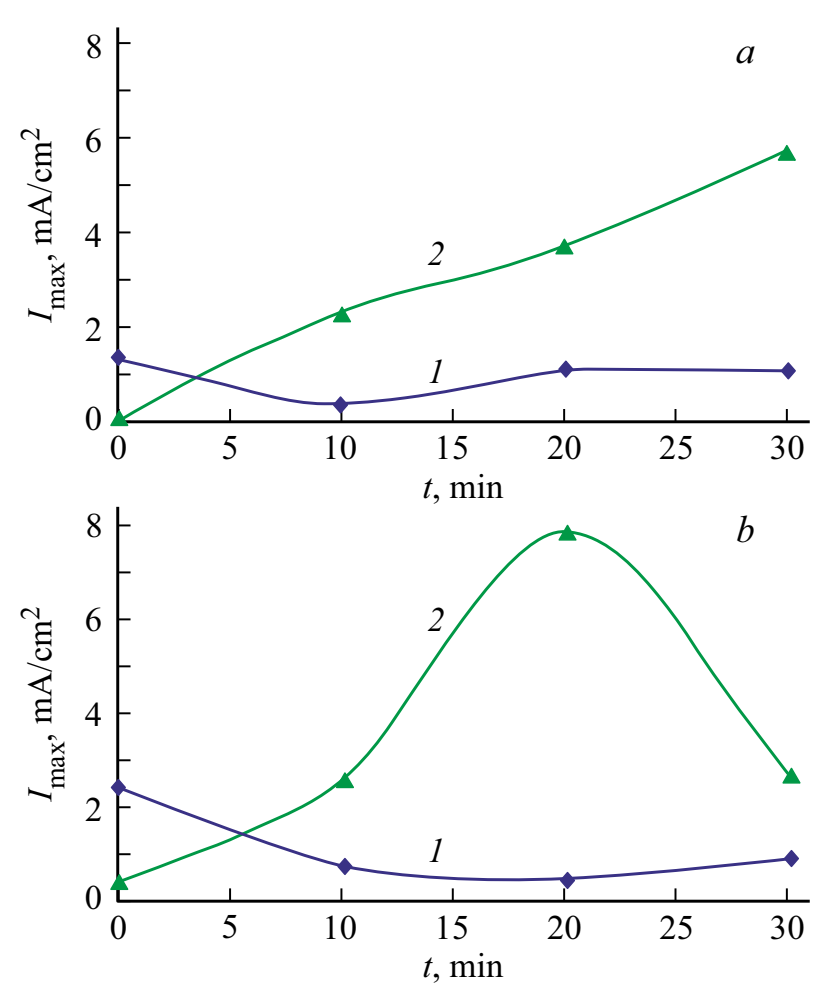

Рис. 3. Зависимости максимальных плотностей токов автоэмиссии пластин кремния $n$ - $(a)$ и $p$-типов $(b)$ проводимости от длительности высокоанизотропного травления для различных видов обработки поверхностей перед осаждением углеродного масочного покрытия: 1 - в плазме хладона-14, 2 - в плазме аргона.

На рис. 3 приведены зависимости максимальных плотностей токов автоэмиссии пластин кремния различных типов проводимости от длительности высокоанизотропного травления после плазменной обработки поверхностей перед осаждением углеродного масочного покрытия в различных рабочих средах. Видно, что при удалении естественного оксидного покрытия в плазме фторсодержащего газа для кристаллов кремния обоих типов проводимости плотности максимальных автоэмиссионных токов при оптимальных длительностях масочного травления практически на порядок меньше, чем при удалении оксидного покрытия в плазме аргона (рис. 2). При плазменной обработке кристаллов кремния в плазме аргона максимальная плотность тока для кристаллов $p$-типа больше максимальной плотности тока для кристаллов $n$-типа.

\section{2. Влияние плазмохимической обработки на ВАХ кремниевых МДП структур}

На рис. 4 приведены ВАХ МДП структур при положительной полярности напряжения на затворе для кристаллов кремния $p$-типа и отрицательной полярности для кристаллов кремния $n$-типа после их плазменного травления в различных плазмообразующих средах. Видно, что для кристаллов $p$-типа при разности потенциалов исток-сток около 3.5 В наблюдается пересечение ВАХ. При $U<3.5$ В большие токи при одинаковых напряжениях реализуются при травлении кристаллов кремния в плазме хладона-14. При $U=2-2.5$ В крутизна ВАХ на структуре, обработанной в плазме аргона, увеличивается, и при $U>3.5$ В токи при травлении в плазме аргона превышают токи в структурах, обработанных в плазме хладона-14. При плазменной обработке кристаллов кремния $n$-типа в среде хладона-14 с отрицательным потенциалом на затворе начало роста тока происходит при меньшем на 3.5-4 В напряжении между истоком и стоком, чем в плазме аргона.

На рис. 5 приведены ВАХ МДП структур на кристаллах кремния различных типов проводимости в зависимости от знака потенциала электрического поля на затворе после плазменной обработки в среде аргона. Можно видеть, что для МДП структур на основе кристаллов кремния $p$-типа при положительном потенциале на затворе и разности потенциалов между истоком и стоком до $3.5 \mathrm{~B}$ токи меньше, чем при отрицательном потенциале. При разности потенциалов исток-сток

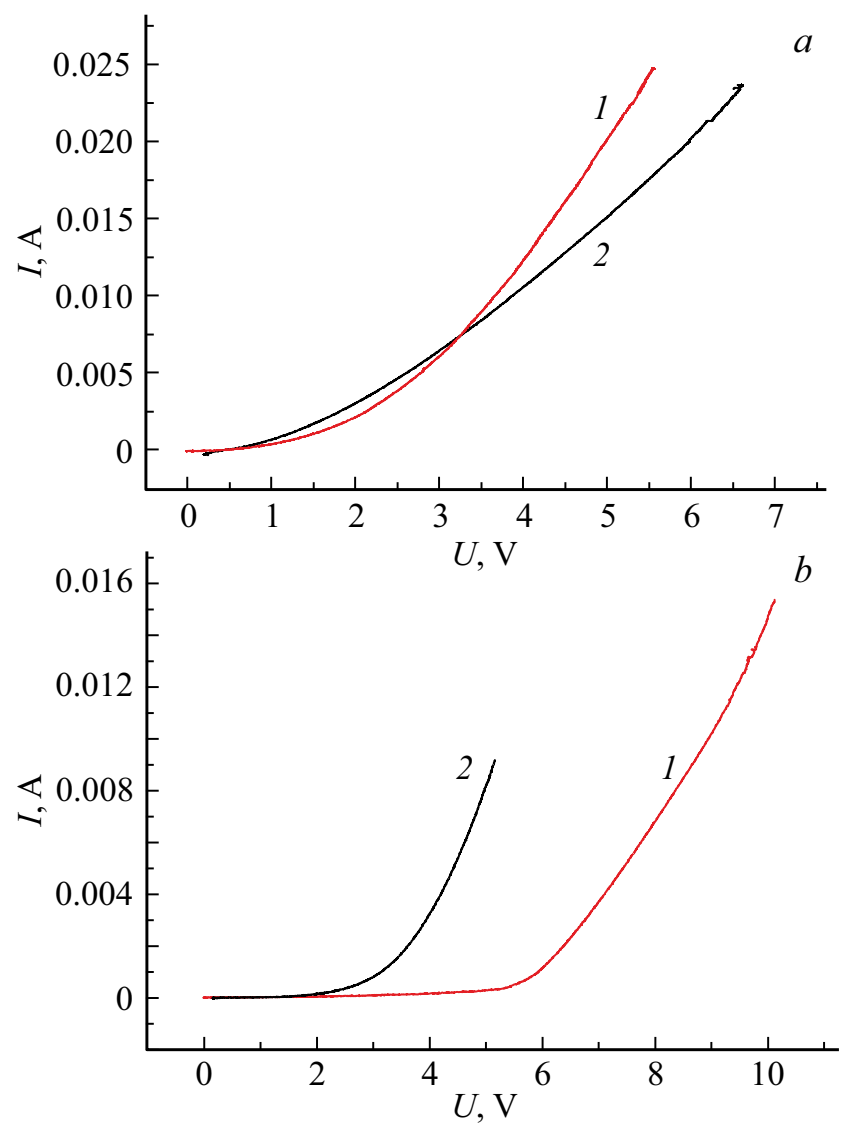

Рис. 4. ВАХ МДП структур при положительной полярности на затворе для кристаллов кремния $p$-типа $(a)$ и отрицательной полярности для кристаллов кремния $n$-типа $(b)$ после травления в различных плазмообразующих средах: 1 - аргоне, 2 - хладоне- 14. 

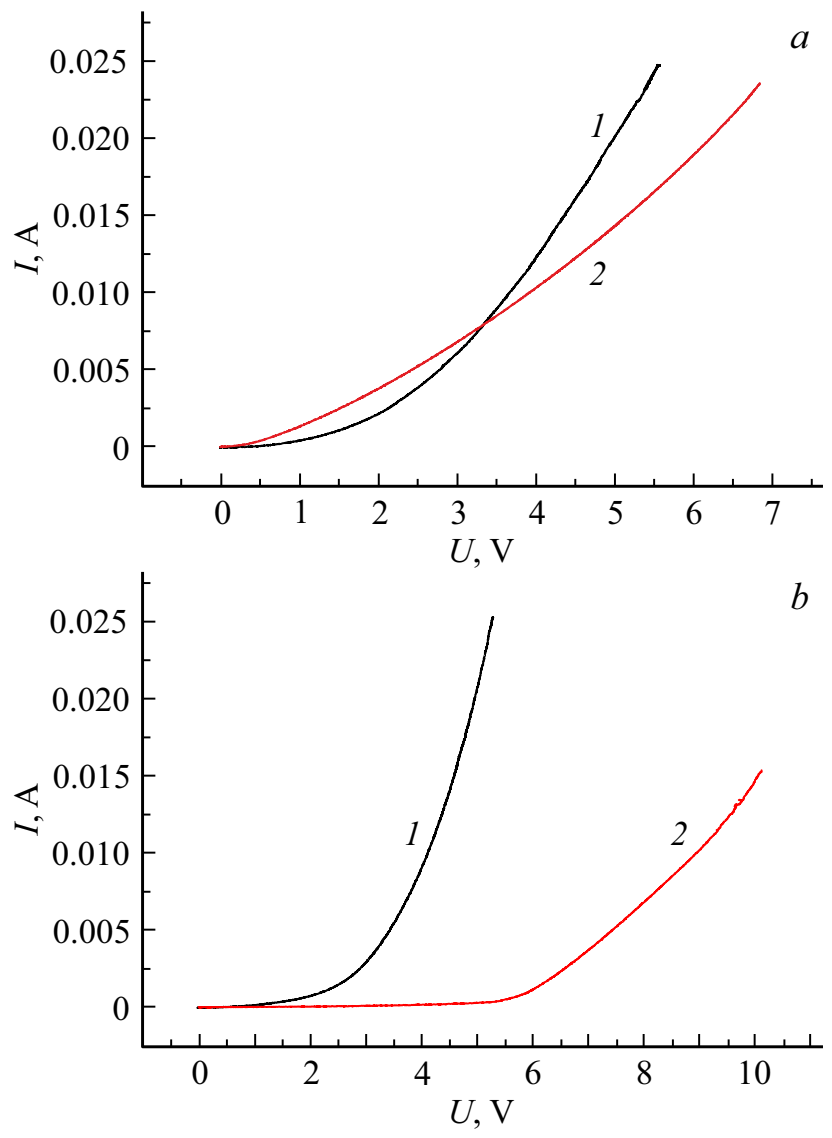

Рис. 5. ВАХ МДП структур после плазменного травления кристаллов кремния $p$ - $(a)$ и $n$-типов $(b)$ в среде аргона при различной полярности на затворе: $1-U>0,2-U<0$.

больше $3.5 \mathrm{~B}$ рост тока ВАХ при положительном потенциале на затворе значительно опережает рост тока при отрицательном потенциале. Для кристаллов $n$-типа кривые ВАХ при положительном потенциале на затворе располагаются в области более низких напряжений между истоком и стоком, а их крутизна и величины токов выше, чем при отрицательном потенциале (рис. $5, b)$. Начало роста тока при положительном потенциале наблюдается при 1.5-2 В, а при отрицательном потенциале - при 5.5-6В и значительно меньшей крутизне BAX.

\section{3. Влияние плазмохимической обработки на BAX поперечного транспорта в кремниевых гетероструктурах}

На рис. 6 приведены в логарифмических координатах BAX поперечного электронного транспорта с прямой полярностью подключения к источнику питания в пленочных структурах $a$-SiC:H на кристаллах кремния (100) $p$-типа после их травления в различных плазмообразующих газовых средах. Можно видеть, что при изменении напряжения в одном и том же интервале значений максимальные токи через гетероструктуры „кремний-туннельно-тонкая пленка $a-\mathrm{SiC}: \mathrm{H}^{“}$ увеличиваются более чем в $10^{4}$ раз при обработке в плазме хладона-14 по сравнению с обработкой в плазме аргона, а значения напряжений, при которых наблюдаются начала роста токов, напротив, уменьшаются от $\sim 10 \mathrm{~B}$ при травлении естественного оксидного покрытия кремния в плазме аргона до $0.1 \mathrm{~B}$ при травлении в плазме $\mathrm{CF}_{4}$. Участки начала роста токов после обработки в аргоне носят характер достаточно резкого (практически скачкообразного) переключения. Перепад токов при этом составляет для плазменной обработки в аргоне 4 порядка, а при обработке в плазме $\mathrm{CF}_{4}$ - около девяти порядков от начального уровня. Плотности токов в последнем случае достигали значений $15 \mathrm{~A} / \mathrm{cm}^{2}$ [5]. При изменении напряжения в обратном направлении токи через структуры во всех случаях выше, чем при изменении напряжения в прямом направлении.

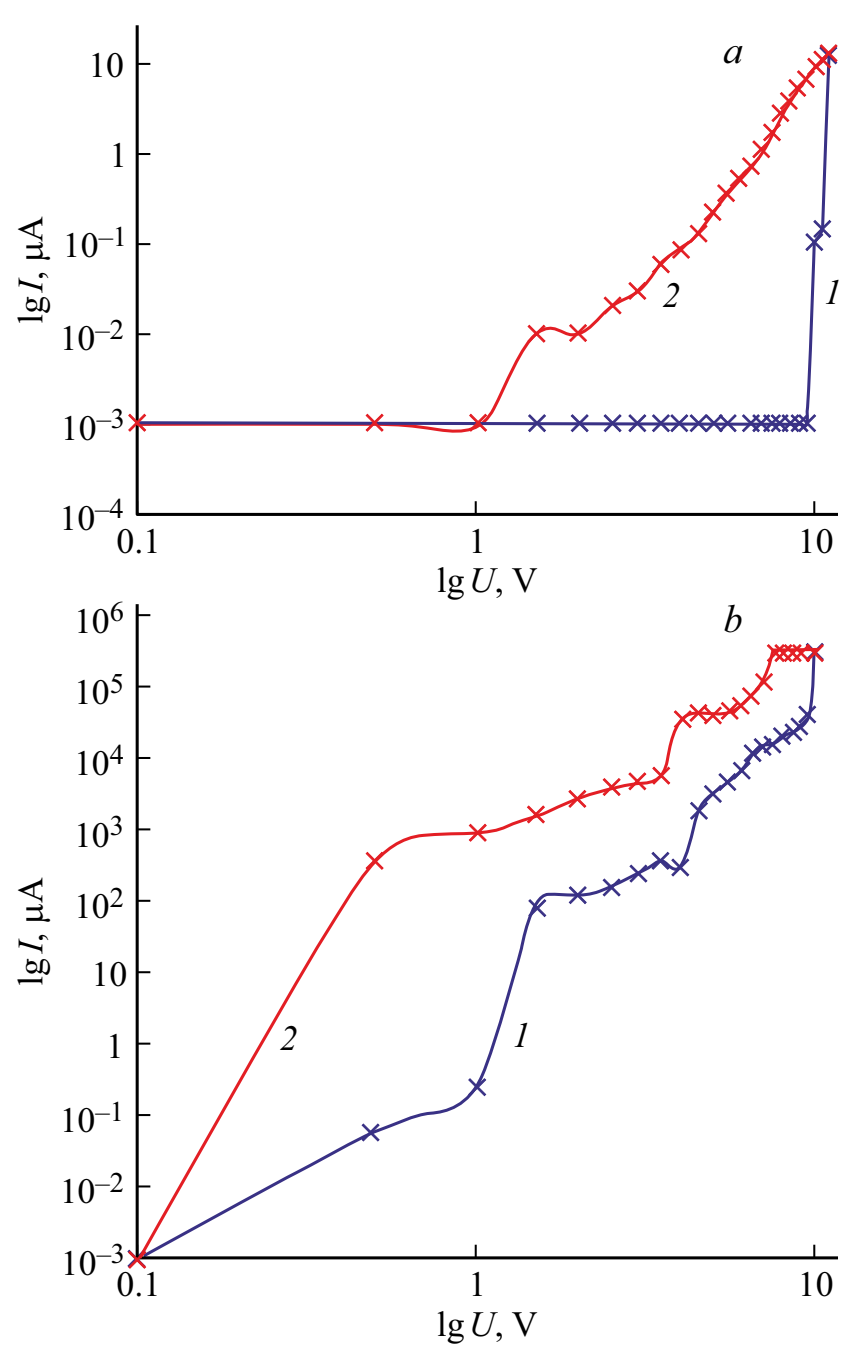

Рис. 6. ВАХ поперечного транспорта электронов в структурах $a$-SiC:Н на кремнии (100) $p$-типа, полученных при прямом (1) и обратном (2) изменении напряжения, после плазменного травления кристаллов кремния в различных газовых средах: $a-$ аргон, $b-$ хладон-14. 


\section{3. Обсуждение результатов}

\section{1. Взаимосвязь ВАХ поперечного транспорта и СВЧ плазмохимической обработки кремния в различных газовых средах}

Как известно [1], виды ВАХ, приведенные на рис. 6, характерны для токов, ограниченных пространственным зарядом (ТОПЗ), которые имеют место в диэлектриках и высокоомных полупроводниках с ловушками захвата носителей. Согласно теории, эти ловушки создают глубокие уровни энергии в запрещенной зоне (так что обратным тепловым выбросом электронов можно пренебречь) и равномерно распределены по объему полупроводника. Участок ВАХ с резким ростом тока, который по терминологии теории ТОПЗ называется участком „полного заполнения ловушек“ (ПЗЛ), является границей между режимом малых омических токов, существующих благодаря присутствию в полупроводниковой структуре некоторого количества равновесных электронов проводимости $n_{0}$, и сильных токов, соответствующих участку с линейным ростом тока, который по терминологии ТОПЗ называется „ловушечным квадратичным законом“ (ЛКЗ). На участке малых омических токов инжектируемые в гетроструктуру из металлического контакта электроны захватываются ловушками происходит формирование области пространственного заряда, индуцированное электрическое поле которого препятствует проникновению электронов из контакта в гетероструктуру. На участке ПЗЛ в начальный момент резкого увеличения тока от напряжения все ловушки оказываются заполненными инжектированными электронами, и тогда их концентрация в зоне проводимости начинает увеличиваться, что приводит к резкому возрастанию тока. На следующем участке ВАХ в области сформировавшегося пространственного заряда токопрохождение описывается законом Мотта. В этом случае ток пропорционален квадрату напряжения. Согласно теории ТОПЗ, напряжение, при котором начинается участок ПЗЛ, связано с концентрацией первоначально незанятых электронами ловушек $\left(p_{0}\right)$ соотношением $U=q p_{0} L^{2} / \varepsilon$, где $q-$ абсолютная величина заряда электрона, $\varepsilon-$ статическая диэлектрическая проницаемость изолятора, $L$ - толщина пленочной структуры.

По аналогии с теорией ТОПЗ можно заключить, что большая длительность участков малых омических токов для гетероструктур после плазменной микрообработки кремния в аргоне может быть обусловлена тем, что возникшие при микрообработке локальные неоднородности и дефекты поверхностной структуры кремния вызывают, по сравнению с обработкой в хладоне, появление дополнительных центров захвата электронов, которые расположены в глубине запрещенной зоны кремния и не могут быть активированы при комнатной температуре.

При использовании низкоэнергетичной плазмы аргона травление пластин кремния осуществляется по ионно-физическому механизму за счет распыления атомов кремния и частиц его естественного окисла ускоренными ионами. В этом случае, благодаря инертности аргона, какие-либо химические связи с поверхностными атомами кремния не образуются. В результате такой обработки поверхность кремния приобретает структуру и плотность оборванных (ненасыщенных) связей, характерных для атомно-чистой поверхности кремния заданной кристаллографической ориентации [2].

При ионно-плазменном травлении кремния в плазме $\mathrm{CF}_{4}$ химически активными частицами являются ионы $\mathrm{C}^{+}, \mathrm{CF}_{n}^{+}$, где $n=1 \ldots 4$, а также радикалы $\mathrm{CF}_{n}$ и нейтральные атомы фтора, которые при хемосорбции образуют адкомплексы $\mathrm{Si}-\mathrm{C}$ и $\mathrm{Si}-\mathrm{F}$ [3]. Хемосорбированные комплексы $\mathrm{SiC}$ и $\mathrm{SiF}$ имеют сильные энергии химической связи (4.55 и 5.6 эВ соответственно) и пассивируют часть оборванных (ненасыщенных) химических связей поверхностных атомов кремния, уменьшая их поверхностную плотность.

Формирование ненасыщенных электронных связей при плазмохимическом травлении приводит к появлению локализованных на поверхности полупроводника состояний, которые в зависимости от степени сродства к электрону и дырке, положения уровня Ферми на поверхности могут проявлять себя как донорные или акцепторные ловушки захвата или рекомбинационные центры [1,2]. Кроме того, присутствие электронных состояний на поверхности полупроводника возмущает электронную структуру в объеме и делает ее энергетически невыгодной. Поэтому поверхностные атомы кремния, имеющие ненасыщенную химическую связь, действуют как дырочные ловушки, заряжаясь положительно при отдаче электрона в зону проводимости полупроводника. Это приводит к образованию на поверхности трехвалентного кремния с положительным зарядом, поверхностная плотность которого выше в случае использования плазмы аргона [6]. При прямом подключении гетероструктуры на кремнии $p$-типа к источнику питания внутреннее поле, вызванное поверхностными зарядами, будет направлено противоположно внешнему, что приводит к ослаблению последнего. В результате этого поперечный ток через структуру при изменении внешнего напряжения возникает только после того, как напряженность от внешнего поля превысит напряженность поля от встроенного заряда. При СВЧ плазменной обработке в атмосфере хладона-14 в результате образования комплексов $\mathrm{SiC}$ и $\mathrm{SiF}$ уменьшается, по сравнению с обработкой в аргоне, величина поверхностного заряда $Q_{s s}$ и, как следствие, уменьшаются внутреннее электрическое поле и степень обеднения приповерхностной области основными носителями. Вследствие этого порог „включения“ проводимости в гетероструктуре после плазменной обработки кремния в среде аргона выше, чем при обработке в хладоне-14. Необходимость преодоления встроенного потенциала для обеспечения поперечного транспорта электронов в гетероструктуре приводит к уменьшению в ней ,действующего“ напряжения. Это уменьшение тем больше, чем больше величина встроенного потенциала. Вследствие этого при приложении одинаковой величины внешнего электрического 
поля поперечный ток через гетероструктуры будет увеличиваться при переходе от обработки в аргоне с максимальной плотностью ненасыщенных поверхностных связей и встроенным потенциалом к обработке в хладоне. После преодоления внутреннего электростатического поля на границе полупроводника и $a-\mathrm{SiH}: \mathrm{H}$ и заполнения всех ловушек устанавливается термодинамически равновесный для данных условий транспорт носителей заряда, при котором инжектированный заряд носителей компенсирует все связанные электростатические заряды на поверхности структуры. Это состояние достигается после резкого увеличения тока на ВАХ. При изменении с этого момента внешнего электрического напряжения на исследуемой структуре в обратном направлении, в результате снижения внешней инжекции происходит постепенное уменьшение пространственного заряда подвижных носителей. Это приводит к уменьшению тока через структуру, который, однако, остается бо́льшим, чем при таком же значении напряжения, но при изменении напряжения в прямом направлении, когда не все ловушки были заполнены. При еще меньших внешних напряжениях и концентрациях подвижных носителей, когда их пространственный заряд становится сравнимым с электростатическим встроенным потенциалом, из-за изменения условий рассеяния подвижность носителей резко падает. Напряжение, при котором происходит резкий спад тока, характеризует величину внутреннего электростатического поля.

\section{2. Влияние встроенного поверхностного потенциала на BAX кремниевыX МдП структур}

У акцепторных полупроводников наличие положительного поверхностного заряда приводит, как известно, к обеднению приповерхностной области основными носителями. Неоднородное распределение заряда приводит к возникновению электростатического потенциала, с направлением электрического поля в объем полупроводника. Ширина области пространственного заряда $Q_{s p}$ и сопротивление обедненного слоя тем больше, чем больше пространственный заряд, который в случае свободной поверхности и отсутствия внешних полей равен и противоположен по знаку заряду в поверхностных состояниях.

При положительной полярности на затворе МДП структуры неосновные носители заряда в полупроводнике $p$-типа туннелируют в ловушечные центры на границе кристалла, частично нейтрализуя приложенный внешний потенциал. Так как при травлении в плазме аргона встроенный пространственный потенциал больше, чем при плазмохимическом травлении в среде хладона-14, ослабление внешнего поля больше в случае аргона. Благодаря этому концентрация электронов в канале проводимости под затвором в случае аргона ниже и при одинаковой небольшой разности потенциалов исток-сток ток в структуре меньше по сравнению с обработкой в плазме хладона-14. При увеличении разности потенциалов между истоком и стоком увеличивается дрейфовая скорость носителей заряда. В случае обработки в плазме хладона-14 суммарное поле, за счет большей поперечной составляющей, действующее на электроны, больше. Увеличение составляющей скорости к поверхности приводит к уменьшению среднего времени свободного пробега электронов в области пространственного заряда и, как следствие, уменьшается их подвижность [1]. По сравнению с обработкой в плазме аргона это приводит к большему диффузному рассеянию электронов при соударениях с поверхностью и уменьшению скорости роста тока с увеличением разности потенциалов между истоком и стоком (рис. 4).

При отрицательной полярности на затворе на границе кристалла кремния сохраняется положительный заряд трехвалентных атомов кремния. Он уменьшает отрицательный потенциал на затворе и увеличивает в поверхностном слое концентрацию электронов. При небольших разностях потенциалов между истоком и стоком это способствует увеличению тока, по сравнению с положительным потенциалом на затворе, когда часть ловушечных центров заполняется электронами и они становятся нейтральными (рис. 5, $a, U<3.5$ В). При увеличении разности потенциалов, за счет увеличения дрейфовой составляющей скорости, увеличивается вероятность соударения электронов с поверхностью и их туннелирование в поверхностные ловушечные центры. Это уменьшает положительный заряд поверхностных ловушечных состояний и подвижность электронов в слое пространственного заряда вблизи поверхности. Следствием этого является уменьшение поверхностной проводимости и скорости роста тока с увеличением разности потенциалов между истоком и стоком (рис. 5, $a$, $U>3.5 \mathrm{~B})$.

При положительной полярности на затворе кремниевых МДП структур $n$-типа электроны туннелируют на ловушечные поверхностные уровни. Возникший встроенный заряд электронов частично нейтрализует положительный заряд затвора и уменьшает действующее поле и концентрацию электронов под затвором. За счет кулоновского взаимодействия между одноименными зарядами основных носителей заряда полупроводника и электронами ловушечных поверхностных центров при приложении разности потенциалов между истоком и стоком уменьшаются нормальная к поверхности составляющая скорости электронов и диффузное рассеяние электронов. В отсутствие диффузного рассеяния с увеличением разности потенциалов между истоком и стоком ток ВАХ быстро увеличивается (кривая 1 на рис. $5, b$ ).

Отрицательное напряжение на затворе формирует положительный встроенный потенциал на границе полупроводника и обедняет канал проводимости основными носителями. В результате этого за счет уменьшения концентрации электронов и увеличения вероятности их туннелирования в дырочные ловушки на поверхности кремния поверхностная проводимость кристалла уменьшается. Ток между истоком и стоком начинает увеличиваться при более высоком напряжения между ними, 
а абсолютные его значения уменьшаются. Смещение между BAX структур, обработанных в плазме аргона, при изменении полярности на затворе с положительной на отрицательную составляет около $4 \mathrm{~B}$ (рис. $5, b$ ).

В случае плазменной обработки кристаллов кремния $n$-типа в среде хладона-14 отрицательное суммарное поле затвора меньше, чем после обработки в среде аргона. Это меньше обедняет канал проводимости основными носителями. В результате этого токи ВАХ в случае обработки в аргоне начинают увеличиваться при более высоком напряжении, а абсолютные их значения уменьшаются. Смещение между ВАХ структур, обработанных в плазме аргона и хладона, составляет около 3 В (рис. $4, b$ ).

Установленное влияние встроенного поверхностного потенциала на крутизну ВАХ МДП устройств на основе кристаллов кремния различных типов проводимости, а также на величину их несимметричности при изменении полярности на затворе может быть использовано, например, при создании специализированных устройств записи и считывания информации, TVS-диодов с несимметричной прямой и обратной ветвями BAX, других приборов и устройств наносистемной техники.

\section{3. Влияние встроенного потенциала на автоэмиссию кристаллов кремния}

Для поверхностно структурированных пластин кремния различных типов проводимости, полученных с удалением естественного оксидного покрытия ионно-физическим распылением в атмосфере аргона (рис. 1, 2), характер зависимостей морфологических параметров от длительностей масочного травления, несмотря на различие скоростей травления, практически одинаков. В отличие от этого характер изменения автоэмиссионных характеристик существенно зависит от типа электропроводности полупроводника. Причиной этого является следующее.

После окончания процесса высокоанизотропного плазмохимического травления кристаллов кремния через островковую кремний-углеродную маску оставшиеся на поверхности кремниевых выступов $\mathrm{Si}-\mathrm{CF}_{m}$ и $\mathrm{Si}-\mathrm{F}$ комплексы, так же как любой другой химический адсорбат, изменяют работу выхода электронов за счет изменения дипольного момента поверхности. Из-за высокой электроотрицательности фтора увеличение дипольного момента особенно сильно в случае высокой концентрации на поверхности кремния $\mathrm{Si}-\mathrm{F}$-диполей. Благодаря высоким скоростям высокоанизотропного травления в плазме хладона-14 с положительным смещением они раньше формируются на пластинах кремния $p$-типа. При длительностях масочного травления пластин $p$-типа больше 20 мин это приводит к росту работы выхода и уменьшению максимальных плотностей автоэмиссионных токов (рис. 3,b). Это происходит несмотря на то, что высоты кремниевых острий продолжают увеличиваться (рис. $1, b$ ), а вместе с ними, согласно представлениям Фаулера и Нордгейма, должны увеличиваться коэффициенты усиления поля и прозрачность диэлектрических барьеров для туннелирования электронов.

После высокоанизотропного плазмохимического травления пластин кремния $n$-типа, которое при положительном смещении на подложкодержателе осуществляется с меньшими скоростями, при одинаковой длительности травления с пластинами p-типа, оставшиеся кремний-углеродные масочные выступы имеют бо́льшую толщину. Преобладающими в них являются $\equiv \mathrm{Si}-\mathrm{C}=\mathrm{C}=\mathrm{CF}_{m}$ комплексы, представляющие собой монослой карбида кремния с фтор-углеродной диэлектрической поверхностной фазой. Диэлектрическая фаза снижает вероятность туннелирования электронов при автоэмиссии. Кроме того, носители, инжектированные из кремниевой подложки в $\mathrm{Si}-\mathrm{CF}_{m}$ поверхностный слой, взаимодействуют с дефектами, расположенными в его объеме. Результатом этого является захват носителей на ловушечные центры, который приводит к дополнительному увеличению порога автоэмиссии. По этой причине порог автоэмиссии на пластинах кремния $n$-типа при длительности травления 20 мин более чем в 2 раза превышает порог начала автоэмиссии для пластин кремния p-типа (рис. 1). При больших длительностях травления за счет конечной селективности травления в системе углеродосодержащая маска-кристаллический кремний толщина масочного покрытия с углеродосодержащими $\equiv \mathrm{Si}-\mathrm{C}=\mathrm{C}=\mathrm{CF}_{m}$ комплексами уменьшается, а высоты кремниевых выступов, напротив, увеличиваются. Это способствует увеличению коэффициентов усиления поля, с одной стороны, и уменьшению встроенного заряда в дефектах кремний-углеродных столбчатых масковых структур, с другой. При длительностях травления пластин кремния $n$-типа 30 мин, когда высоты выступов имеют наибольшие значения, порог начала автоэмиссии опускается до $28 \mathrm{~B} /$ мкм, а плотность максимального автоэмиссионного тока увеличивается до $6 \mathrm{MA} / \mathrm{cm}^{2}$.

Для пластин кремния $p$-типа минимальные значения порогов автоэмиссии, а также максимальные значения поверхностных плотностей выступов и плотностей автоэмиссионных токов реализуются при длительностях масочного травления 20 мин. Минимальный порог возбуждения автоэмиссии составляет 32 В/мкм, а максимальные плотности автоэмиссионных токов достигают $8 \mathrm{MA} / \mathrm{cm}^{2}$.

Полученные плотности автоэмиссионных токов для поверхностно-наноструктурированных кристаллов кремния обоих типов проводимостей практически на 2 порядка превосходят плотности токов с эмиттерных решеток, полученных с использованием традиционных микроэлектронных технологий [7].

При плазменном удалении естественного оксидного покрытия на кристаллах кремния с последующим осаждением углеродных островковых масковых покрытий приводит, как показано выше, к формированию под масковым покрытием встроенного поверхностного потенциала с направлением вектора электрического поля в глубь полупроводника. Встроенный потенциал и приповерхностный пространственный заряд на кремнии 
при плазмохимической обработке в среде хладона-14 меньше, чем при обработке в аргоне, и более устойчив к внешним электростатическим воздействиям. В случае кристаллов кремния с электронным типом проводимости за счет поверхностной электронной автокомпенсации это различие менее значимо, чем при плазменной обработке кристаллов кремния $p$-типа [2]. За счет большей величины встроенного потенциала после распыления естественного оксидного покрытия ионами аргона, пондеромоторные нагрузки от внешнего электрического поля на кристаллическую решетку кремния уменьшаются. Результатом этого являются реализация в кремниевых структурах $p$-типа при оптимальных длительностях высокоанизотропного маскового покрытия с удалением естественного оксидного покрытия травлением в плазме аргона больших по величине максимальных плотностей автоэмиссионных токов, по сравнению со структурами $n$-типа и травлением во фторсодержащей плазме (рис. 3).

\section{4. Заключение}

Низкоэнергетическая СВЧ плазменная микрообработка пластин монокристаллического кремния в различных по химической активности газовых средах позволяет различным образом модифицировать („перестраивать“) электронную структуру и свойства поверхности. Модификация связана с перераспределением плотности заряда в приповерхностной области и определяется природой используемых плазмохимических сред. Валентность составляющих их химических элементов по отношению к кремнию и прочность образующихся химических связей способствуют формированию устойчивых насыщенных связей поверхностных атомов кремния с различной плотностью. Оставшиеся ненасыщенные поверхностные связи участвуют в перестройке электронной структуры приповерхностной области полупроводника. Это приводит к возникновению встроенного электростатического потенциала и изменению приповерхностных электрофизических свойств, которые определяют закономерности транспорта и туннельной эмиссии электронов в пленочных гетероструктурах, созданных на пластинах кремния после соответствующей плазмохимической микрообработки. При низкоэнергетичной плазменной микрообработке в среде аргона в результате его химической инертности на поверхности пластин кремния образуются ненасыщенные электронные связи с максимальной поверхностной плотностью. Это вызывает наиболее сильные изменения приповерхностных электрофизических свойств кремния и условий транспорта электронов. Плазменная микрообработка в среде хладона-14 пассивирует часть оборванных связей поверхностных атомов кремния. Вследствие этого встроенный потенциал и приповерхностный пространственный заряд на кремнии после плазменной микрообработки в хладоне-14 меньше, чем при обработке в плазме аргона. Поэтому BAX поперечного транспорта электронов в исследуемой гетероструктуре для этого случая имеет меньшую величину участка малых омических токов, которая, согласно теории ТОПЗ, пропорциональна концентрации первоначально незанятых электронами ловушек в структуре.

Для каждого типа полупроводника при удалении естественного оксидного покрытия с использованием ионно-плазменного или плазмохимического травления взаимосвязь морфологических и автоэмиссионных характеристик может быть описана в рамках теории Фаулера-Нордгейма с учетом изменения свойств поверхностных фаз на вершинах кремниевых острий, которые происходят в процессах масочного травления. Изменения в свойствах поверхностных фаз приводят к изменению суммарного дипольного момента поверхности эмиссионных острий, прозрачности потенциальных барьеров, и, следовательно, автоэмиссионных характеристик полученных структур.

Исследование выполнено за счет гранта Российского научного фонда (проект № 16-19-10033).

\section{Список литературы}

[1] В.Л. Бонч-Бруевич, С.Г. Калашников. Физика полупроводников (М., Наука, 1977).

[2] К. Оура, В.Г. Лифшиц, А.А. Саранин, А.В. Зотов, М. Катаяма. Введение в физику поверхности (М., Наука, 2006).

[3] Р.К. Яфаров. Физика СВЧ вакуумно-плазменных нанотехнологий (М., Физматлит, 2009).

[4] Р.К. Яфаров, В.Я. Шаныгин. ФТП, 51 (4), 558 (2017).

[5] Д.В. Будко, Р.К. Яфаров. Тез. докл. VI Всеросс. конф. молодых ученых „Наноэлектроника, нанофотоника $и$ нелинейная физика“ (Саратов, Россия, 2011) с. 13.

[6] Р.К. Яфаров, С.А. Климова. ЖТФ, 84 (3), 103 (2014).

[7] Fei Zhao, Jian-hua Deng, Dan-dan Zhao, Ke-fan Chen, Guo-an Cheng, Rui-ting Zheng. J. Nanosci. Nanotechn., 10, 1 (2010).

Редактор Г.А. Оганесян

\section{Effect of plasma-chemical modification of the surface on electronic transport and work function in silicon crystals}

\section{R.K. Yafarov}

Saratov branch of the Institution

of Russian academy of sciences Kotel'nikov Institute of Radio Engineering and Electronics, Russian Academy of Sciences, 410019 Saratov, Russia

\footnotetext{
Abstract The regularities of the modification of the surface of silicon crystals under microwave plasma microprocessing in various chemically active gas media are studied. It is shown that the modification is due to the formation of built-in surface potentials, which, depending on the type of conductivity of semiconductors, affect the field emission properties and nearsurface electronic transport in devices made on their basis.
} 